\title{
Environmental Inequality and Pollution Advantage among Immigrants in the United States
}

\author{
Abstract \\ Environmental inequality scholarship has paid little attention to the disproportional exposure of \\ immigrants in the United States (U.S.) to unfavorable environmental conditions. This study \\ investigates whether new international migrants in the U.S. are exposed to environmental \\ hazards and how this pattern varies among immigrant subpopulations (e.g., Hispanics, Asian, \\ European). We combine sociodemographic information from the American Community Survey \\ with toxicity-weighted chemical concentrations (Toxics Release Inventory) to model the \\ relationship between toxin exposure and the relative population of recent immigrants across \\ Public Use Microdata Areas (PUMAs, n=2,054) during 2005-2011. Results from spatial panel \\ models show that immigrants tend to be less exposed to toxins, suggesting resilience instead of \\ vulnerability. This pattern was pronounced among immigrants from Europe and Latin America \\ (excluding Mexico). However, our results revealed that Mexican immigrants are \\ disproportionately exposed to environmental hazards in wealthy regions.
}

\section{Keywords}

Environmental hazards, environmental inequality, international immigrants, spatial panel models, USA, toxin release 


\section{Introduction}

Environmental inequality and its adverse health effects have received substantial public attention worldwide (Goodnough, 2016; Laurian \& Funderburg, 2014; Nichols, 2001). Particularly the disproportionate exposure to unfavorable environmental conditions is of interest to researchers and policy makers alike. Unfavorable environmental conditions, or hazards, include natural and anthropogenic extreme events (e.g., earthquakes, chemical spills) or elements in the built environment (e.g., nuclear power plants) that pose a threat to the wellbeing of individuals (Burton et al., 1978; Hunter, 2005). Researchers have traditionally viewed immigrants as vulnerable (Bustamante, 2002) due to the following reasons: (1) weak legal standing, (2) low socioeconomic status, (3) limited English-language proficiency (Derose et al., 2007; Kim et al., 2011), and (4) racial and ethnic minority status, based on which immigrants might face institutional and individual discrimination similar to native-born minority groups (Noh et al., 2007; Viruell-Fuentes, 2007). While these factors do not automatically translate into exposure, they create social vulnerability and undermine immigrants' resilience and capacity to withstand environmental hazards. Immigrants may find it harder to respond to a disaster, which can undermine their capacity to cope with future impacts and amplify their vulnerability (Maantay \& Maroko, 2009; Wisner et al., 2003). Immigrants' legal, socioeconomic and ethnic/racial status affects their knowledge of and access to environmental hazards awareness and assistance programs (Wisner et al., 2003). This study is guided by the following questions: How does the level of industrial pollution in an area affect the immigration rates in that area? How does this effect vary by the country/region of origin?

The paper is organized as follows: the background section provides an overview of environmental inequality research and identifies gaps relating to immigrants' exposure to 
environmental hazards, that are further tested in the paper. The background section is followed by the description of data and methods used in the study, followed by the discussion of findings.

\section{Background}

Environmental inequality studies have shown that environmental risks are distributed unequally, with racial and ethnic minorities, low-income households, and other vulnerable populations disproportionally exposed to environmental hazards (Anderton et al., 1994; Bowen, 2002). Individual socioeconomic characteristics are important determinants of exposure to environmental hazards among the native-born U.S. population (Crowder \& Downey, 2010; Mohai \& Bryant, 1992). Wealthier, more educated persons are more likely to reside in environmentally safe areas (Mohai et al., 2009), while discriminatory housing market practices may expose minorities to environmental hazards regardless of their educational level (Crowder \& Downey, 2010). However, these associations have been mostly tested for the general U.S. population and the relationship among socioeconomic factors, immigrant status, and exposure to environmental hazards remains unclear.

Immigrants in the U.S. are highly diverse and show varying levels of human capital (e.g., education) and social capital (e.g., access to networks) affecting economic success, residential patterns (Garip, 2008; Vigdor, 2002), and associated environmental hazard exposure at the place of residence (Crowder \& Downey, 2010; Lievanos, 2015). Heterogeneity in immigrants' education is well-recorded: immigrants from Mexico on average have 9 years of schooling as compared to Chinese immigrants with 13.6 years of schooling (Chiswick \& DebBurman, 2004). Highly educated immigrants may find employment in medical, finance, or technology sectors with little exposure to environmental hazards at work and with sufficient income to afford housing in environmentally safe neighborhoods. By contrast, poorly educated immigrants may 
be predominantly employed in environmentally hazardous occupations in industrial manufacturing and construction with limited income, forcing these migrants to settle in inexpensive, environmentally unsafe neighborhoods.

Few studies have investigated the differential environmental inequality among the foreign-born population of the U.S. (Collins et al., 2011; Hernandez et al., 2015; Hunter, 2000). These studies reveal that immigrants' English-language skills predict possible exposure to environmental hazards, and that U.S. counties with larger proportions of immigrants frequently contain environmental hazards. However, these studies do not distinguish between recent immigrants and the foreign-born population at large.

Social vulnerability emerges because social inequalities affect people's exposure to risks and their ability to respond to and withstand risks (Wisner et al., 2003). Even though immigrants might be similar to native-born minorities in their socio-demographic characteristics (Hunter, 2000) and have better overall health (Gee, et al., 2006), they warrant special attention because of their legal standing and wide prevalence of limited English proficiency (Zeng \& Batalova, 2016). The consequences of exposure for immigrants can be extremely debilitating because of their limited economic resources. As such, repairing damages and seeking health care can take a substantial toll on their resources and disrupt employment (Maantay \& Maroko, 2009; Wisner et al., 2003). Immigrants may also lack support systems to protect themselves from the discriminatory attitudes of the majority population. Notable case studies document that environmental inequality can be exacerbated by the disproportionate siting of toxic facilities in immigrant communities (Cole \& Foster, 2001; Laurian \& Funderburg, 2014) and restrictive immigration policies on the grounds that excessive immigration depletes America's ecosystems (Park \& Pellow, 2011). All of these factors, combined with evidence from previous research, 
indicate that immigrants are potentially more susceptible to exposure to environmental hazards. To further elucidate the issue of environmental inequality among immigrants, it is beneficial to adopt a detailed approach and differentiate immigrants by country/region of origin.

In sum, while there has been some research on ethnic/racial minority groups and environmental inequality, we know little about environmental inequality among immigrants. This study contributes to the literature through a detailed investigation of environmental inequality among immigrants with an explicit focus on the following three knowledge gaps and associated research questions:

1) Existing research has paid little attention to environmental inequality among immigrants even though they represent a potentially vulnerable population and their share in the total U.S. population is increasing. We therefore ask: What is the effect of industrial pollution levels on international migration rates to PUMAs?

2) No work has investigated differential exposure to environmental hazards among immigrants originating from different regions/countries. Knowledge about differential exposure among immigrant groups will improve the scope of environmental hazards awareness and coordination programs, housing and resettlement support. Thus, we expand our first research question to ask: What is the effect of industrial pollution levels on immigration rates conditional upon immigrants' country/region of origin?

3) We know little about the interaction among socioeconomic factors, immigrant status and exposure to unfavorable environmental conditions and consequently ask: Do immigration rates differ by the level of wealth and industrial pollution in a given area? 


\section{Data and Methods}

\subsection{Data}

Sociodemographic data were obtained from IPUMS-USA (Ruggles et al., 2015) and represent single-year samples from the American Community Survey (ACS) from 2005 to 2011. The selection of the time period from 2005 to 2011 was guided by the availability of ACS data at the Public Use Microdata Area (PUMA) level, which is the lowest geographic level provided by IPUMS-USA (Ruggles et al., 2015). According to the U.S. Census Bureau definition (2015b), PUMAs represent statistical geographic areas that are nested within states and contain a minimum of 100,000 people for confidentiality purposes. The U.S. Census Bureau redraws PUMA boundaries for every decennial census. As such, the most recent year of our data sample was 2011, after which new 2010 PUMA boundaries were implemented into the ACS. The earliest year in which the PUMA variable was available was 2005. This study relies on a total of 2,054 PUMAs in the continental U.S. The ACS distinguishes international immigrants from internal migrants and the native-born population. The data obtained from IPUMS-USA were aggregated to the PUMA level. We chose to employ individual microdata aggregated at the PUMA level (in contrast to county-level aggregates) because it: (1) provides the flexibility to perform additional analyses at the household level in future research; and (2) allowed us to link important geographical and environmental variables from the Terra Populus data extract engine.

We used the Risk-Screening Environmental Indicators (RSEI) model data provided by the United States Environmental Protection Agency (EPA, 2015) as a source of environmental hazards data. The RSEI is a model representing hazard-based and risk-related impacts of chemical releases (in pounds) reported to the Toxics Release Inventory (TRI). 


\subsection{Variable construction}

\subsubsection{Outcome variables}

Our six outcome variables represent: (1) the number of all international migrants per 10,000 people per PUMA; (2-6) the numbers of international migrants from the following regions/countries per 10,000 people per PUMA ${ }^{1}$ : Europe, Latin America (excluding Mexicans, referred to as Latin America in the rest of this paper), Mexico, Asia (excluding Chinese, referred to as Asia in the rest of the paper), and China. We focus our analysis on these selected subpopulations because they contribute the largest proportions to the foreign-born population of the U.S. (MPI, 2015b). Individuals were classified as international immigrants if they resided in a different country other than the U.S. one year ago. Figure 1 depicts the spatial distribution of immigrants across the United States. While the largest proportion of Mexican migrants can be found in the southwestern border regions, Chinese migrants tend to cluster in the Midwest. Immigrants from Europe, Latin America, and Asia do not exhibit clear spatial patterns.

\footnotetext{
${ }^{1}$ All outcome variables were constructed using the total population of a PUMA in the denominator (including both native-born and foreign-born). For example, the outcome measure for Mexican immigrants was constructed the following way:

Immigration rate for Mexican immigrants $=\frac{\text { number of Mexican immigrants in a PUMA in a given year }}{\text { total population of PUMA in that year }} * 10,000$.
} 

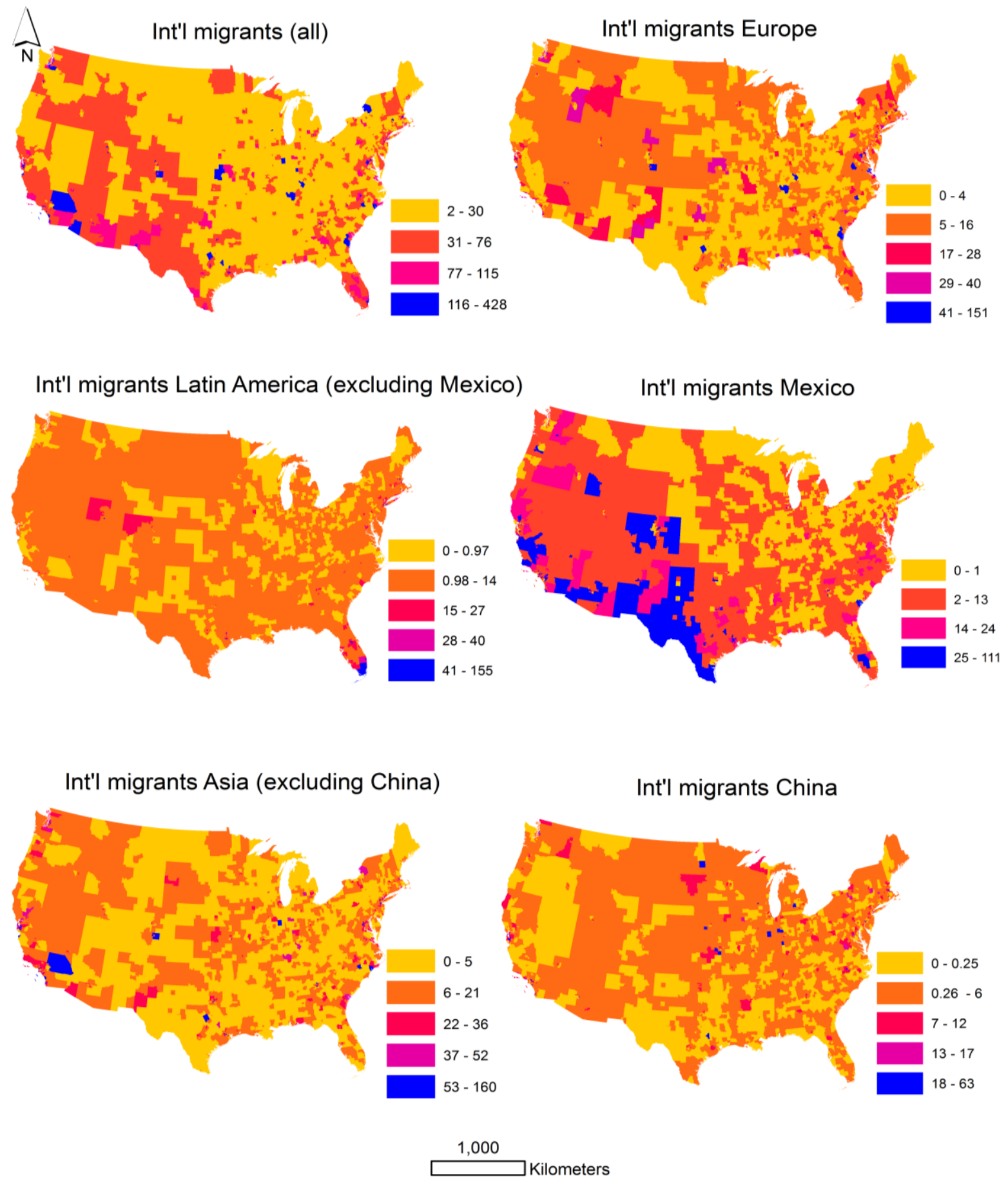

Figure 1. Spatial distribution of immigrants in the United States, averaged across 2005-2011. Note: numbers reflect counts of immigrants per 10,000 people per PUMA. 


\subsubsection{Primary predictor}

Our measure of the exposure to environmental hazards represents toxicity-weighted releases of chemicals in milligrams per cubic meter $\left(\mathrm{mg} / \mathrm{m}^{3}\right)$ per PUMA averaged for 2010 2012. We relied on the RSEI (Risk-Screening Environmental Indicators) model, produced by EPA with TRI data as input. RSEI provides estimates of the amount of toxins released and their risk to human health. The input TRI data includes air and surface water releases from industrial facilities but does not contain information about mobile sources of pollution. Reporting chemical releases and transfers to off-site facilities is mandated by the Emergency Planning and Community Right-to-Know Act of 1986 (EPA, 2015). In 2012, 623 chemicals and chemical categories were subject to mandatory reporting. RSEI weights reported emissions to produce risk estimates of exposure to certain chemicals. The constructed risk-based indicators take into account chemicals' toxicity, sources of release into the environment, rate of decay, and the

pathway to human exposure (EPA, 2015). Based on oral and inhalation exposure pathways, the EPA assigns toxicity weights to chemical releases, with higher weights for increasing levels of toxicity and associated human health risks. TRI does not include all toxic chemicals but only those with mandated reporting, assumes that the chemical concentrations are the same for outdoor and indoor exposure, and does not estimate dermal and food ingestion pathways of exposure.

The RSEI Geographic Microdata used in this paper are represented as a grid of $810 \mathrm{~m}^{2}$ (28 x 28 meters) cells covering the continental U.S. We aggregated the data to the PUMA level by overlaying PUMA boundaries on the grid, summing concentrations from all the cells within each PUMA, and dividing the sum by the number of cells falling inside the PUMA. These steps were performed in PostGIS and R Statistical Environment (PostGIS, 2015; RCoreTeam, 2015). To account for skewed distribution and approximate normality, the continuous measure of toxin 
release was log-transformed. The variable was used as time-invariant average of 2010-2012 because the EPA only provides RSEI Geographic Microdata for these years. While EPA makes single year data for earlier periods available on request, merging different years of data is unreliable and erroneous because of frequent improvements in algorithms and toxicity weights contributing to the RSEI (Wayne Davis, Senior Environmental Scientist at EPA, personal communications). According to the TRI National Analysis conducted by the EPA (2017), total releases from the TRI facilities changed from 4,362 million pounds in 2005 to 4,114 million pounds in 2011, which makes it appropriate to use the toxin release measure as time-invariant.

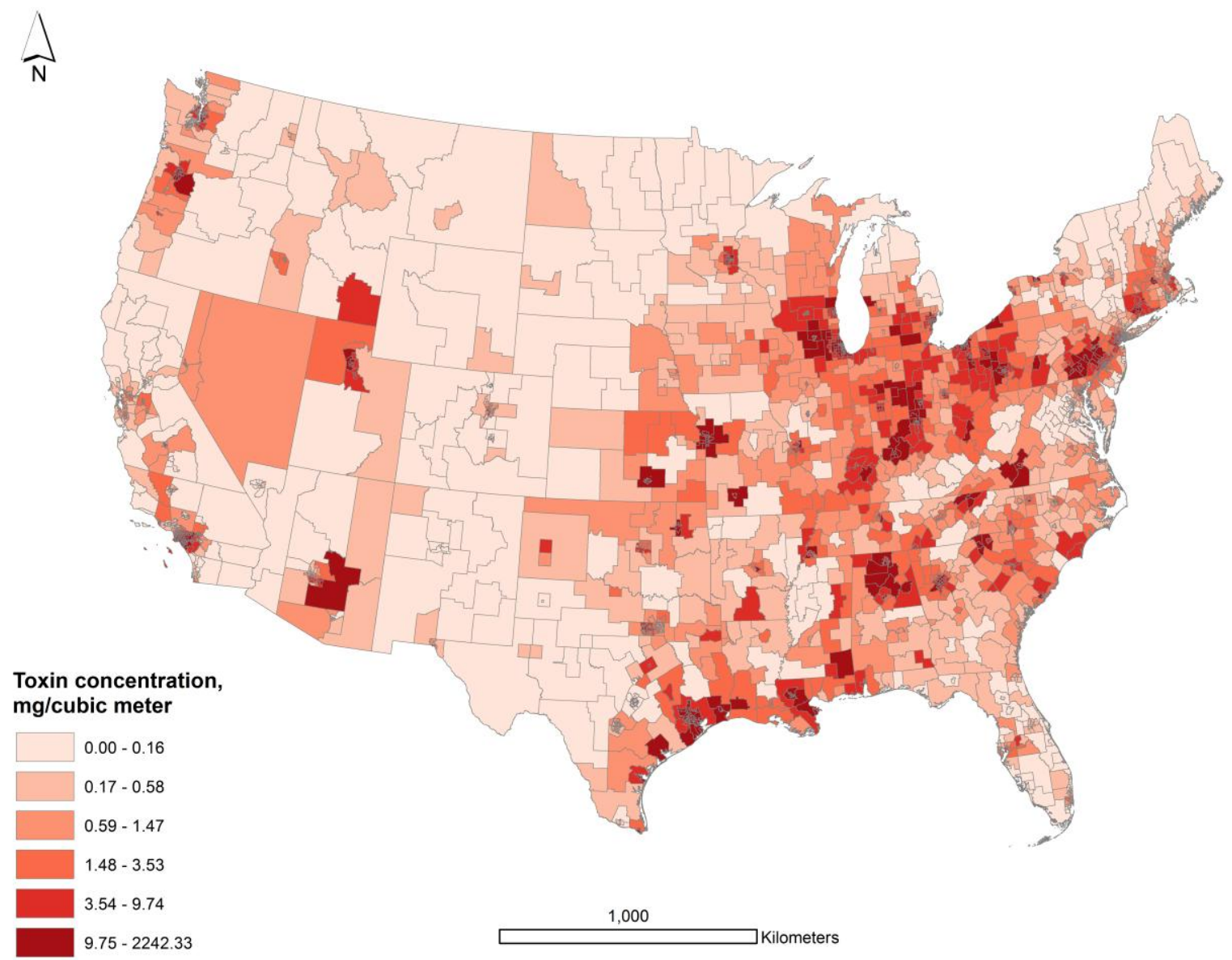

Figure 2. Average toxicity-weighted chemical concentrations for U.S. PUMAs during 2010-2012 
A clear spatial pattern in toxin concentration is evident at the PUMA level (Figure 2). The highest concentrations are observed in the Rust Belt and near the Gulf of Mexico and are linked to steel and oil production, respectively (Chay \& Greenstone, 2003).

\subsubsection{Control variables}

Prior research suggests a positive association between socioeconomic conditions in an area and exposure to environmental hazards (Been, 1994; Crowder \& Downey, 2010; Freeman, 1972; Mohai \& Bryant, 1992; Mohai et al., 2009). To account for socioeconomic conditions, we computed the average income and average proportion of adults employed for each PUMA. To account for the skewed distribution, the income measure was log transformed. Areas' gender composition has been shown to be an important determinant of migration (Davis \& Winters, 2001; De Jong, 2000; Shauman, 2010), and we control for PUMA's gender composition as the proportion of males in the population. We also account for employment in manufacturing, mining and construction as well as the proportion of urban area in a PUMA, all of which are important factors in predicting the presence of environmental risks (Lievanos, 2015; Ard, 2015; Hunter, 2000). The socioeconomic measures were computed as time-varying controls based on ACS data from IPUMS-USA (Ruggles et al., 2015), while the area urban was derived from MODIS Land Cover data obtained from Terra Populus (Kugler et al., 2015; MPC, 2013) and merged with the ACS data using PUMA identifiers.

Amenity migration caused by the attractiveness of area's natural or cultural features has received increasing attention in recent research and has been associated with unique migration patterns to the American West and Sun Belt (Gober \& Zonn, 1983; Massey, 2010; Partridge, 2010). One of the distinctive features of amenity migration is the movement of people because of the draw of weather, landscapes and ambience (Glaeser, 2007; Partridge, 2010), which is often undertaken by retirees. We rely on the average maximum temperature and precipitation for the 
years 2010-2012 as well as retiree dependency ratio (proportion of the population ages 64+) to account for the effects of amenity migration. Temperature and precipitation measures were obtained from Terra Populus and originate from the Climate Research Unit Time Series (CRUTS) data set (Harris et al., 2014). Summary statistics for all the variables can be found in Table 1 below.

\subsection{Estimation strategy}

Both toxin release and immigration show distinct spatial patterns (Figures 1 and 2). A formal test (Morans I, Anselin, 1995) revealed significant spatial autocorrelation in the residuals of regular OLS models. Ignoring spatial autocorrelation may lead to biased inferential statistics and increases the chance of committing a Type I error (rejecting the null hypothesis if it is true) (Anselin et al., 2000). As such, we employed spatial panel models that effectively account for spatial autocorrelation as well as heterogeneity across time (Call \& Voss, 2016; Millo \& Piras, 2012). We fitted spatial panel models using the package splm within the R Statistical Environment (Call \& Voss, 2016; Millo \& Piras, 2012). The splm package has been frequently used in the analysis of time-space dependent phenomena (Call \& Voss, 2016; Millo \& Piras, 2012).

We estimated spatial lag models with time period fixed effects. Spatial lag specification refers to a model that creates a spatially lagged dependent variable based on a spatial weights matrix. Spatial lag models account for spatial spillover effects, acknowledging that the values of the dependent variable in one unit depend on the values of the dependent variable in neighboring units. As such, spatial lag models account for network effects and the presence of migrant systems (DeWaard et al., 2012) by statistically accounting for the fact that places with high concentrations of migrants tend to attract the largest migrant inflows. 
Within our spatial models, a neighborhood was defined as comprised of the eight nearest PUMAs in line with prior research (Franco-Lopez et al., 2001; McRoberts et al., 2002; Schelling, 1969). In contrast to other neighborhood definitions, this specification guarantees that all units have the same number of neighbors, even when located in border regions or spatially isolated. We performed a robustness test with various neighborhood definitions (e.g., 12-nearest neighbors, queen, rook) and found similar effects. The spatial matrix was constructed using a polygon shapefile of PUMA boundaries obtained from Terra Populus (Kugler et al., 2015; MPC, 2013)

Our models predict the number of immigrants relative to the total population $\left(\mathrm{y}_{\mathrm{it}}\right)$ for each location $(i)$ and year $(t)$ and can be written as:

$$
y_{i t}=\alpha+\beta_{0}+\beta_{n}\left(x_{n}\right)+\beta_{1}\left(\operatorname{tox}_{i}\right)+\rho W y_{i t}+u_{i t}
$$

In equation 1 , year fixed effects are represented by coefficient $\alpha$. The parameter $\beta_{0}$ represents the intercept while $\beta_{\mathrm{n}}$ constitutes a vector of regression coefficients of various sociodemographic and geographical characteristics $\left(x_{n}\right)$. The control variables are included as time-varying $(i t)$ and time-constant (i) measures, as indicated by the generic subscript $n$. The parameter $\beta_{1}$ reflects the effect of the time-invariant measure of toxin release $\left(\right.$ tox $\left._{i}\right)$ on migrant prevalence as the central focus of this analysis. The coefficient $\rho$ is the spatial lag of the dependent variable and $W$ is the spatial weights matrix, while $u_{i t}$ constitutes the conventional error term.

In the spatial lag model the value of the dependent variable $y$ at location $i$ depends on the values of predictor variable $x$ at location $i$ and the values of $x$ at other locations, which, in turn, depend on the values on $x$ in other neighboring locations (Anselin \& Rey, 2014). As such, the value of $y$ depends on all the values of $x$. The indirect effect (also known as spatial multiplier effect) takes into account the effect of $x$ on $y$ from neighboring locations. As a result, the total 
effect of $x$ on $y$ in spatial lag models is comprised of the direct and indirect effects (Anselin, 2003; Anselin \& Rey, 2014; Kim et al., 2003). The direct effect of a predictor variable $x$ on the dependent variable $y$ is reflected by the conventional regression coefficient $(\beta(\mathrm{x}))$. The indirect $\left(\beta\left(x^{\prime}\right)\right)$ and total $\left(\beta\left(x^{\prime}\right)\right)$ effect, due to the spatial multiplier effect, can be estimated using the following expressions:

$$
\begin{aligned}
& \beta\left(x^{\prime}\right)=\beta(x) \rho /(1-\rho) \\
& \beta\left(x^{\prime \prime}\right)=\beta\left(x^{\prime}\right)+\beta(x)
\end{aligned}
$$

In equation $2, \beta(x)$ is the regression coefficient for variable $x$, and $\rho$ is the spatial lag. The total effect $\left(\beta\left(x^{\prime}\right)\right)$ consists of the sum of indirect $\left(\beta\left(x^{\prime}\right)\right)$ and direct $(\beta(\mathrm{x}))$ effects (Equation 3). We estimate the indirect, direct and total effects of toxin release on the immigration rates across PUMAs.

Finally, to explore spatial patterns in the association of toxin release and the presence of immigrants, we employed a geographically weighted regression (GWR). We employed GWR for those outcome variables for which we observe a significant interaction effect between industrial pollution and income. Unlike the traditional regression approach that produces one estimate for the entire study area, GWR relies on a user-specified distance/radius to produce estimates that vary across the study area. We relied on a bi-square adaptive kernel to fit a local regression model for each PUMA. The results of a GWR allow for an exploration of spatial patterns that are otherwise hidden in global estimates (Fotheringham et al., 2002; Gollini et al., 2015). GWR has been effectively used to explore spatial patterns of interactions between environmental and social factors (Gilbert \& Chakraborty, 2011; Mennis \& Jordan, 2005; Nawrotzki \& Bakhtsiyarava, 2016). 


\section{Results and Discussion}

\subsection{General trends}

Average migration rates for each study year reveal general trends with respect to the timing of migration streams from each country/region (Table 1). From 2005 to 2011 there were on average 51 international immigrants per 10,000 people in PUMAs. The average migration rate varied little across time, reaching 54 per 10,000 in 2011 and showing a small dip to 47 immigrants per 10,000 people in 2009 , likely related to the economic recession and the U.S. housing bust (Ellis et al., 2014; Johnson, 2013). 
Table 1. Descriptive statistics for the variables used in the analysis exploring toxin exposure among various immigrant groups residing in the U.S. during 2005-2011

\begin{tabular}{|c|c|c|c|c|c|c|c|c|c|c|c|c|}
\hline & \multirow[t]{2}{*}{ Unit } & \multirow[t]{2}{*}{$\mathrm{TV}^{\mathrm{d}}$} & \multirow[t]{2}{*}{ Min } & \multirow[t]{2}{*}{$\operatorname{Max}$} & \multirow[t]{2}{*}{ SD } & \multicolumn{7}{|c|}{ Sample mean } \\
\hline & & & & & & 2005 & 2006 & 2007 & 2008 & 2009 & 2010 & 2011 \\
\hline \multicolumn{13}{|l|}{ Outcome variables } \\
\hline \multicolumn{13}{|l|}{ International immigrants } \\
\hline All $^{\text {a }}$ & $1 / 10000$ & Yes & 0 & 662.1 & 51.5 & 51.26 & 52.1 & 50.82 & 53.91 & 47.14 & 50.23 & 53.61 \\
\hline Europe & $1 / 10000$ & Yes & 0 & 288.6 & 17.15 & 10.91 & 10.44 & 9.76 & 10.57 & 8.89 & 9.29 & 10.15 \\
\hline Latin America ${ }^{b}$ & $1 / 10000$ & Yes & 0 & 220.1 & 16.69 & 7.95 & 7.64 & 7.22 & 7.52 & 6.91 & 7.78 & 7.77 \\
\hline Mexico & $1 / 10000$ & Yes & 0 & 220.2 & 16.16 & 10.28 & 8.86 & 7.63 & 7.2 & 5.41 & 4.8 & 5.82 \\
\hline $\mathrm{Asia}^{\mathrm{c}}$ & $1 / 10000$ & Yes & 0 & 273.3 & 21.34 & 10.85 & 12.23 & 12.95 & 13.96 & 12.55 & 13.4 & 15.06 \\
\hline China & $1 / 10000$ & Yes & 0 & 139.8 & 8.75 & 1.99 & 2.61 & 2.91 & 3.1 & 3.12 & 3.59 & 4.5 \\
\hline \multicolumn{13}{|l|}{ Environmental hazard } \\
\hline Toxin release & $\mathrm{mg} / \mathrm{m} 3$ & No & 0 & 2242 & 56.36 & 9.31 & 9.31 & 9.31 & 9.31 & 9.31 & 9.31 & 9.31 \\
\hline \multicolumn{13}{|l|}{ Control variables } \\
\hline Males & $\%$ & Yes & 40 & 62.53 & 1.86 & 48.08 & 48.45 & 48.41 & 48.36 & 48.39 & 48.49 & 48.62 \\
\hline Unemployed & $\%$ & Yes & 0.9 & 19.46 & 2.06 & 4.25 & 3.83 & 3.78 & 3.8 & 5.89 & 6.48 & 5.96 \\
\hline Employed in manufacturing & $\%$ & Yes & 0.6 & 38.85 & 5.5 & 11.78 & 11.39 & 11.19 & 11.09 & 10.79 & 10.61 & 10.4 \\
\hline Employed in mining & $\%$ & Yes & 0 & 16.15 & 1.3 & 0.42 & 0.45 & 0.47 & 0.51 & 0.5 & 0.5 & 0.53 \\
\hline Employed in construction & $\%$ & Yes & 0.6 & 22.54 & 2.33 & 6.91 & 7.26 & 7.2 & 6.96 & 6.81 & 6.51 & 6.35 \\
\hline Household income & USD 1,000 & Yes & 23 & 201.8 & 21.73 & 61.39 & 62.01 & 63.71 & 63.27 & 62.49 & 59.98 & 58.37 \\
\hline Retiree dependency ratio & $\%$ & Yes & 5.5 & 191 & 8.58 & 22.51 & 22.72 & 23.18 & 23.94 & 24.35 & 24.64 & 25.75 \\
\hline Area urban & $\%$ & No & 0 & 100 & 36.78 & 33.97 & 33.97 & 33.97 & 33.97 & 33.97 & 33.97 & 33.97 \\
\hline Average precipitation & $\mathrm{mm} / \mathrm{month}$ & No & 6.3 & 206 & 30.16 & 82.57 & 82.57 & 82.57 & 82.57 & 82.57 & 82.57 & 82.57 \\
\hline Average max temperature & deg. $\mathrm{C}$ & No & 9.9 & 31.06 & 4.54 & 20.1 & 20.1 & 20.1 & 20.1 & 20.1 & 20.1 & 20.1 \\
\hline
\end{tabular}

Notes: ${ }^{\mathrm{a}}$ All immigrants combined; ${ }^{\mathrm{b}}$ excluding Mexico; ${ }^{\mathrm{c}}$ excluding China; ${ }^{\mathrm{d}}$ TV column indicates whether variable's values were time-varying (Yes) or time-constant (No); Values for Min, Max, and Standard Deviation (SD) refer to the complete sample across all years (2005-2011); Sample size: PUMA-years: $n=14,378$, PUMAs: $n=2,054$; In a preliminary analysis we included variables reflecting English-language skills and educational attainment as important predictors of residence in environmentally unsafe neighborhoods (Lievanos, 2015; Hunter, 2000). However, these variables showed high correlation with other variables of interest and were excluded from the final analysis to avoid issues of multicollinearity. With these adjustments, the Variance Inflation Factor (VIF) diagnostic remained below 1.67, demonstrating that multicollinearity does not bias our estimates. 
Table 2 shows results from spatial lag models with time fixed effects estimating PUMAlevel presence of various immigrant groups. The coefficient estimates for the various control variables in the model for all migrant groups combined (Model "All” in Table 2) confirm patterns observed in prior research. For example, highest immigration rates were observed for PUMAs with higher proportions of males, low levels of unemployment and employment in the primary (mining) and secondary (manufacturing, construction) sectors (Zeng \& Batalova, 2016), characterized by a less affluent, younger population (Hunter, 2000), higher levels of urbanization, and a warmer and slightly more humid climate (Poston et al., 2009) Although largely similar, some of these trends differ in magnitude and direction by immigrant groups, likely as a result of occupational preferences and differences in immigrants' socioeconomic conditions (MPI, 2015a, 2016a).

\subsection{Toxin release effects}

Including the toxin release measure in all the models allows us to answer our first research question (What is the effect of industrial pollution levels on international migration to PUMAs conditional upon PUMAs' socioeconomic characteristics?). In contrast to the assumption that immigrants in the U.S. are socially vulnerable and thus more likely to migrate to environmentally unsafe places (Hunter, 2000; Lievanos, 2015), our results indicate that international immigrants tend to migrate to less polluted areas, and therefore demonstrate a pollution advantage. A one unit $\left(\log \mathrm{mg} / \mathrm{m}^{3}\right)$ increase in the toxin concentration in a PUMA is associated with a decrease in the number of international immigrants by 1.17 per 10,000 people. 
Table 2. Spatial panel models predicting the proportions of various immigrant groups relative to the native-born population among U.S. PUMAs during 2005-2011

\begin{tabular}{|c|c|c|c|c|c|c|c|c|c|c|c|c|}
\hline & \multicolumn{12}{|c|}{ International immigrants } \\
\hline & \multicolumn{2}{|c|}{$\mathrm{All}^{\mathrm{c}}$} & \multicolumn{2}{|c|}{ Europe } & \multicolumn{2}{|c|}{ Latin America $^{\mathrm{d}}$} & \multicolumn{2}{|c|}{ Mexico } & \multicolumn{2}{|c|}{$\operatorname{Asia}^{\mathrm{e}}$} & \multicolumn{2}{|c|}{ China } \\
\hline & $b$ & sig. & $b$ & sig. & $\mathrm{b}$ & sig. & $\mathrm{b}$ & sig. & $\mathrm{b}$ & sig. & $\mathrm{b}$ & sig. \\
\hline Intercept & -77.72 & $* * *$ & -18.19 & $* * *$ & -10.73 & $* *$ & -3.53 & & -39.34 & $* * *$ & -3.84 & \\
\hline Males $^{b}$ & 31.45 & $* * *$ & 4.2 & $* * *$ & 2.45 & $* * *$ & 4.68 & $* * *$ & 11.3 & $* * *$ & 2.36 & $* * *$ \\
\hline Unemployed $^{\mathrm{b}}$ & -20.47 & $* * *$ & -5.44 & $* * *$ & -0.47 & & -5.99 & $* * *$ & -4.83 & $* * *$ & -1.01 & $*$ \\
\hline Employed in manufacturing $^{\mathrm{b}}$ & -13.47 & $* * *$ & -3.78 & $* * *$ & -1.7 & $* * *$ & -0.1 & & -2.8 & $* * *$ & -0.97 & $* * *$ \\
\hline Employed in mining ${ }^{b}$ & -25.8 & $* * *$ & -5.89 & $* * *$ & 0.43 & & -3.89 & $* * *$ & -7.74 & $* * *$ & -1.04 & \\
\hline Employed in construction ${ }^{b}$ & -38.42 & $* * *$ & -11.53 & $* * *$ & -0.39 & & 8.6 & $* * *$ & -17.79 & $* * *$ & -5.77 & $* * *$ \\
\hline Household income & -3.57 & $*$ & 4.69 & $* * *$ & -1.78 & $* * *$ & -4.98 & $* * *$ & 2.01 & $* *$ & 0.17 & \\
\hline Retiree dep. ratio $^{b}$ & -5.68 & $* * *$ & -0.96 & $* * *$ & -1.16 & $* * *$ & -1.55 & $* * *$ & -1.56 & $* * *$ & -0.2 & $*$ \\
\hline Area urban ${ }^{b}$ & 2.41 & $* * *$ & 0.12 & $*$ & 0.84 & $* * *$ & 0.69 & $* * *$ & 0.48 & $* * *$ & 0.14 & $* * *$ \\
\hline Average precipitation ${ }^{b}$ & 0.41 & $* *$ & 0.12 & $*$ & 0.9 & $* * *$ & -0.78 & $* * *$ & 0 & & 0.01 & \\
\hline Average max temperature ${ }^{b}$ & 9.78 & $* * *$ & 0.3 & & 2.17 & $* * *$ & 5.27 & $* * *$ & 1.88 & $* * *$ & -0.43 & $*$ \\
\hline \multicolumn{13}{|l|}{ Effects of toxin release } \\
\hline Toxin release (direct effect) & -1.17 & $* * *$ & -0.28 & $* * *$ & -0.51 & $* * *$ & -0.11 & & -0.15 & & -0.01 & \\
\hline Toxin release (indirect effect) ${ }^{a}$ & -1.22 & & -0.19 & & -0.65 & & -0.07 & & -0.12 & & -0.01 & \\
\hline Toxin release (total effect) ${ }^{a}$ & -2.39 & & -0.47 & & -1.16 & & -0.18 & & -0.27 & & -0.02 & \\
\hline \multicolumn{13}{|l|}{ Model Statistics } \\
\hline Spatial lag & 0.51 & $* * *$ & 0.41 & $* * *$ & 0.56 & $* * *$ & 0.4 & $* * *$ & 0.45 & $* * *$ & 0.38 & $* * *$ \\
\hline AIC & 244,296 & & 216,425 & & 212,762 & & 213,278 & & 222,011 & & 198,214 & \\
\hline $\mathrm{R}^{2}$ & 0.4 & & 0.21 & & 0.37 & & 0.28 & & 0.26 & & 0.13 & \\
\hline Pseudo $\mathrm{R}^{2}$ Spatial & 0.27 & & 0.14 & & 0.22 & & 0.22 & & 0.16 & & 0.07 & \\
\hline
\end{tabular}

Notes: Sample size for all models: PUMA-years: $n=14,378$, PUMAs: $n=2,054 ;{ }^{a}$ the computation of indirect and total effect of the spatial multiplier does not permit obtaining significance test statistics and values should be interpreted in terms of effect size; ${ }^{\mathrm{b}}$ parameter estimates reflect an incremental change of $10 \%$ in the predictor variable; ${ }^{\mathrm{c}}$ All immigrants combined; ${ }^{\mathrm{d}}$ excluding Mexico; ${ }^{\mathrm{e}}$ excluding China. As a more conservative goodness of fit measure, we report the Pseudo $\mathrm{R}^{2}$ Spatial, which accounts for spatial dependence within the data. Pseudo $\mathrm{R}^{2}$ Spatial is computed by squaring the correlation between the observed and fitted values of models' outcome variables (Anselin and Rey, 2014). * p<0.05; ** $\mathrm{p}<0.01 ; * * * \mathrm{p}<0.001$ 
In addition to the direct toxin release effect, the spatial lag models permit estimation of an indirect effect, mediated through spatial dependence on neighboring PUMAs. This indirect effect (1.22 per 10,000 people) is similar in size to the direct effect, leading to a doubling of the total effect with a decrease in the total immigrant population of 2.39 per 10,000 people for each oneunit increase in toxin release. Our finding of a pollution advantage reveals a possible pathway for the dynamics underlying the healthy immigrant paradox: lower exposure to environmental toxins may translate into better health outcomes among immigrant populations (Evans \& Kantrowitz, 2002), which in turn explains the observed health advantage of immigrants over the native-born population in the U.S. (Hunt et al., 2003; McGlade et al., 2004; Wingate \& Alexander, 2006).

As a robustness check, we performed a jackknife procedure, randomly excluding $10 \%$ of PUMAs from the sample and re-estimating the models across 100 iterations (Nawrotzki et al., 2015). We also tested for influential time periods by omitting one year at a time from the sample and refitting the models (Jennings \& Gray, 2015). Both procedures indicated a high degree of robustness of our results.

Focusing on specific immigrant groups allows us to answer our second research question (What is the effect of industrial pollution levels on immigration rates conditional upon immigrants' country/region of origin?). Our results reveal contrasting patterns of exposure to environmental hazards among various immigrant groups. For example, immigrants from Europe and Latin America show a pollution advantage and tend to migrate to less polluted areas. Employment in a polluting sector (construction, mining, manufacturing) is an important predictor of exposure to environmental hazards, and European immigrants as a group are less likely to be employed in such industries than both the native-born population and other immigrant groups (USCB, 2015a). Moreover, as opposed to the native-born U.S. population and 
overall foreign-born populations, European immigrants are on average older and wealthier (MPI, 2015a; USCB, 2015a), with implications for residential choice and migration to environmentally safe areas. Generally, Latin Americans tend to favor service occupations and are less likely to be employed in industrial and transportation-related occupations compared to other immigrant groups in the U.S. (MPI, 2016b). A trend towards amenity migration and a documented desire for a higher quality of life as reflected in better schools, affordable housing, and low crime rates (Massey, 2010), may make Latin American immigrants more likely to reside in environmentally safe areas.

In contrast, for Mexican, Chinese, and Asian immigrants we found no relationship between toxin release and their concentration in PUMAs, indicating exposure patterns comparable to their native-born counterparts. Employment in polluting industries such as oilproduction and mining (Bauer et al., 2002), as well as lower average socioeconomic status (USCB, 2015a) may explain Mexican immigrants' lack of a pollution advantage. The confluence of below-average education and low income (USCB, 2015a) may force Mexicans to settle in areas of low rental prices but high environmental burden (cf. Crowder \& Downey, 2010). However, as a group, Asian immigrants are often employed in the fields of science, engineering and technology (MPI, 2016a), and show overall higher levels of income (MPI, 2016a), making the lack of a pollution advantage a surprise.

In sum, our results reveal that international immigrants in the U.S. overall do not disproportionally migrate to environmentally unsafe areas.

\subsection{Interactions}

Area-level wealth and socioeconomic conditions have been identified as important determinants of exposure to environmental pollutants (Freeman, 1972; Hunter, 2000). In order to 
answer our third research question (Do immigration rates differ by the level of wealth and industrial pollution in a given area?), we interacted the toxin release measure with average PUMA income. Table 3 reveals a positive directionality for most immigrant groups (except for European migrants), which implies that the association between toxin release and immigration rates increases in strength for wealthier PUMAs. However, the interaction coefficient only reached significance for Mexican migrants.

Table 3. Interactions between toxin release and income on the expected proportion of immigrants within each PUMA

\begin{tabular}{lccccccc}
\hline & Inc & \multicolumn{3}{c}{ Tox } & \multicolumn{3}{c}{ Inc x Tox } \\
& $\mathrm{b}$ & sig. & $\mathrm{b}$ & sig. & $\mathrm{b}$ & sig. \\
\hline International immigrants & & & & & & & \\
All $^{\mathrm{a}}$ & -3.63 & $*$ & -1.16 & $* * *$ & 0.56 & \\
Europe & 4.72 & $* * *$ & -0.28 & $* * *$ & -0.32 & \\
Latin America $^{\mathrm{b}}$ & -1.79 & $* * *$ & -0.51 & $* * *$ & 0.03 & \\
Mexico $_{\text {Asia }}{ }^{\mathrm{c}}$ & -5.08 & $* * *$ & -0.09 & & 0.86 & $* * *$ \\
China & 1.97 & $* *$ & -0.14 & & 0.41 & \\
\hline
\end{tabular}

Notes: ${ }^{a}$ All immigrants combined; ${ }^{b}$ excluding Mexico; ${ }^{c}$ excluding China; Interactions were obtained by estimating full models with all socioeconomic and geographic controls as per Table 2; Inc $=$ estimates of average PUMA income (logged); Tox = estimates of toxin release (logged); Inc $\mathrm{x}$ Tox $=$ estimates of interaction effects between the measures of income and toxin release. Toxin release and income variables were centered;

$* \mathrm{p}<0.05 ; * * \mathrm{p}<0.01 ; * * * \mathrm{p}<0.001$. 


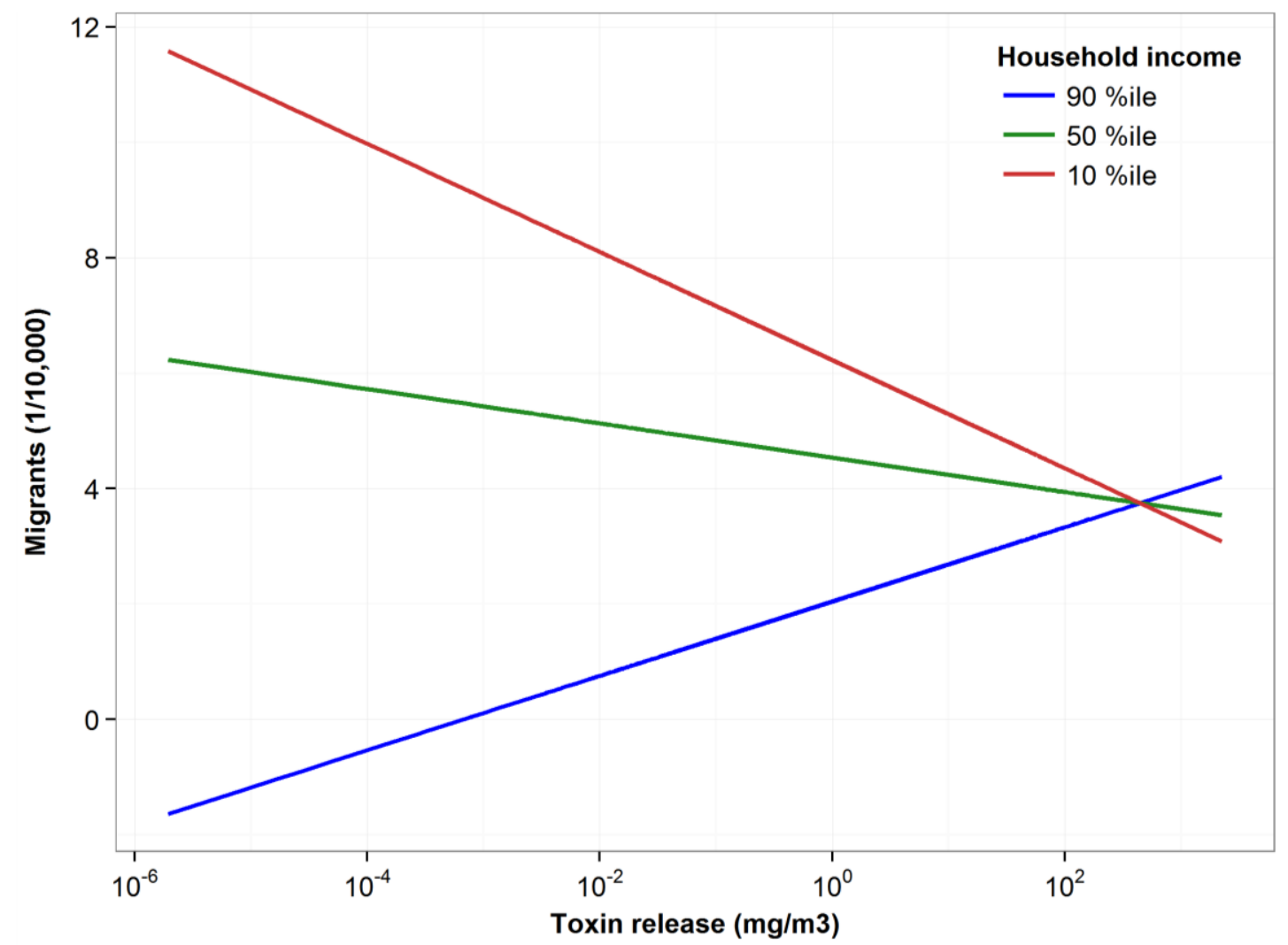

Figure 3. Interaction effect between toxin release and income on the expected proportion of Mexican immigrants within each PUMA

Figure 3 reveals that in PUMAS of average wealth (50\%ile, green line) the association between toxin release and the presence of Mexican migrants is negative but weak. This negative trend (slope) becomes stronger among poor PUMAs (10\%ile, red line), where the association resembles the general relationship observed for the combined immigrant population as well as for European immigrants. In these economically marginalized regions, Mexican immigrants display the pollution advantage and tend to migrate to less polluted areas. However, in the wealthiest PUMAs (90\%ile, blue line), this relationship is inverted. In groups of these highincome PUMAs, Mexican immigrants disproportionally migrate to areas of highest toxin release. This pattern may be explained by Mexican immigrants' generally low socioeconomic status as well as discriminatory housing market practices (Crowder \& Downey, 2010) and unique legal 
status (Rivera-Batiz, 2004), preventing them from residing in environmentally safe areas when housing prices are high and rental markets are controlled by discriminatory elites.

We employed a GWR to explore local patterns of the interaction between toxin release and PUMA-level wealth on the presence of Mexican immigrants. The strongest positive interaction effects (colored red and orange) are observed along the Gulf Coast, in the West and Midwest (Figure 4), which are known for their oil-production and steel manufacturing (Mani \& Wheeler, 1998). In comparatively high-income PUMAs in those areas, Mexican immigrants are disproportionately exposed to toxin release and do not exhibit a pollution advantage.

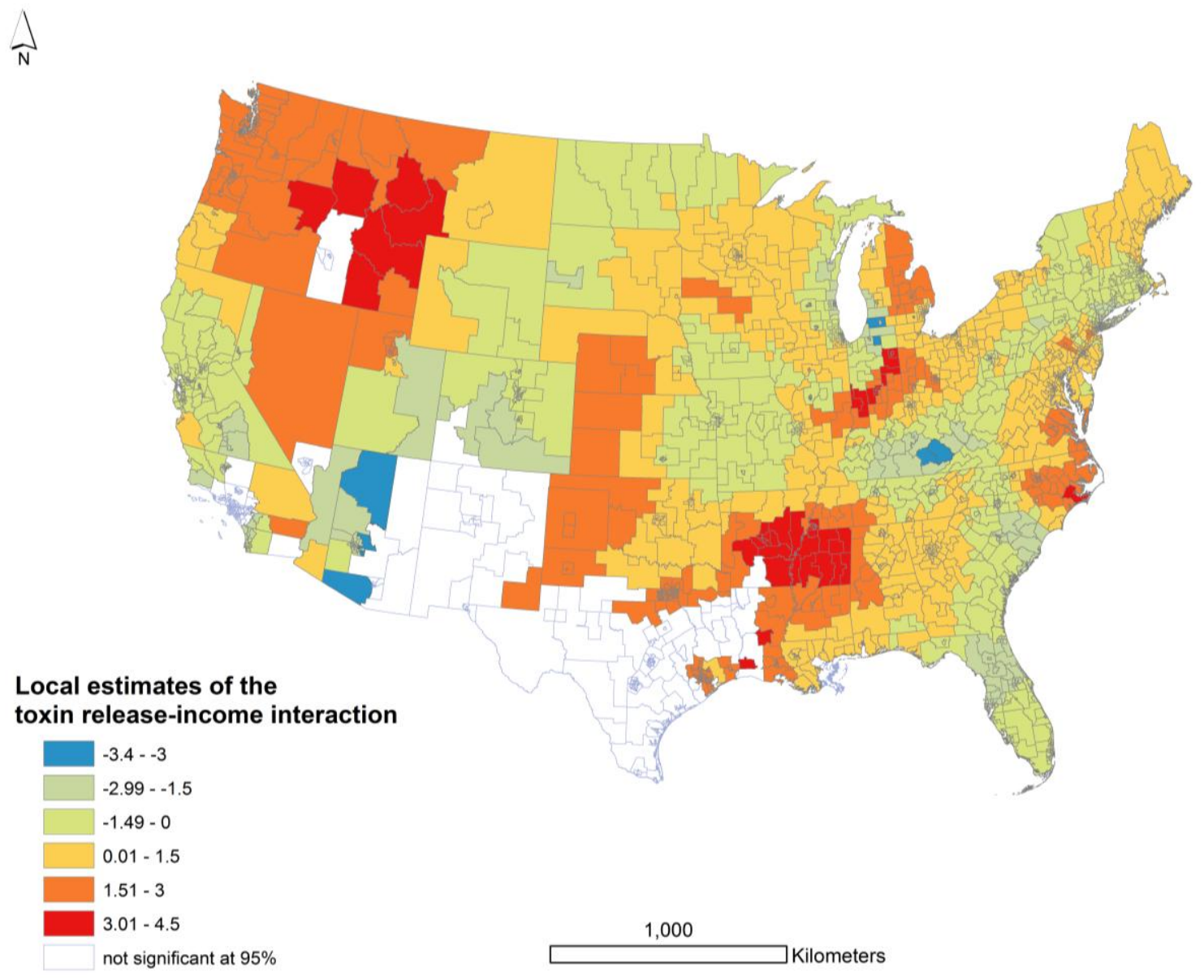

Figure 4. Local estimates of the effect of interaction between toxin release and income on the presence of Mexican immigrants in a given PUMA.

Note: GWR point estimates for each PUMA are derived from a local sub-sample of $n=144$ neighboring units. The optimal bandwidth of $n=144$ was determined empirically via cross-validation. 


\section{Conclusion}

In this paper we have investigated whether immigrants in the U.S. migrate to environmentally hazardous areas. This study builds on previous research on environmental inequality by expanding the definition of vulnerable populations to immigrants of various origins. One strength of our approach is the use of spatial panel models that help account for complex space-time dynamics in the relationship between immigration rates and toxin exposure. Our results reveal that international immigrants in the U.S. overall do not disproportionally migrate to environmentally unsafe areas. On the contrary, they tend to migrate to less polluted areas and thus demonstrate a high degree of resilience. However, this pollution advantage is not shared by all immigrant groups alike and only emerges for immigrants from Europe and Latin America (excluding Mexico), perhaps due to the unique occupational selection and socioeconomic characteristics of these immigrant groups. (MPI, 2015a, 2016b). Interaction models and results from GWR reveal that in groups of high-income PUMAs, Mexican immigrants are disproportionally exposed to environmental hazards, thus not exhibiting any pollution advantage. These findings suggest that immigrants cannot be directly equated with vulnerable minority groups when it comes to exposure to environmental hazards and that immigrants from different regions/countries exhibit different patterns of exposure. Future research may employ qualitative and quantitative approaches to investigate the underlying dynamics that differentially protect certain immigrant groups from toxin exposure. Future research should also investigate another understudied group - native-born ethnic minorities - and their experiences of environmental inequality.

Despite a careful modeling approach and multiple robustness checks, a number of limitations deserve mention. First, the RSEI data did not include pollution from mobile sources and do not include all known toxins but only those with mandated reporting. Second, a classic 
problem in geographic research is the modifiable areal unit problem in that there can be shifts in parameter estimates (Higgs \& Langford, 2009; Maantay, 2007; Openshaw, 1984), so using a finer scale than PUMAs would result in more accurate estimates of exposure. We use individual microdata aggregated to the PUMA level (in contrast to county-level aggregates) to be able to investigate the observed relationships at the household-level in future research. Finally, we did not take into account shifts in immigration policies, which could have impacted immigration rates for certain immigrant groups (Massey, 2010), although our time fixed effects account for some of these changes.

Our study has important policy implications. The results show that Mexican immigrants are especially exposed to environmental hazards in high-income areas. Given Mexican immigrants' overall low levels of education and limited English proficiency, we recommend that communities should publish relevant information for toxin exposure prevention and the introduction of hazardous facilities in their neighborhood not only in English but also in Spanish. Besides preventing disproportionate siting of hazardous facilities efforts should also be made to mitigate the existing consequences of such siting, including housing support, planting of trees and protecting water sources. Such policies may help ameliorate environmental inequality among vulnerable subpopulations, such as Mexican migrants, and will help create a society where every individual can exercise their human right to a safe and healthy environment (UNEP, 2016). 


\section{Acknowledgments}

The authors gratefully acknowledge support from the Minnesota Population Center (\#R24 HD041023), funded through grants from the Eunice Kennedy Shriver National Institute for Child Health and Human Development (NICHD). This work also received support from the National Science Foundation funded Terra Populus project (NSF Award ACI-0940818). The authors wish to acknowledge the United States Environmental Protection Agency for making the TRI data and exhaustive documentation publicly available. We extend our gratitude to Steven Manson, Jack DeWaard, Rob Warren and Tracy Kugler for helpful comments. We express our gratitude to Joshua Donato for his help with the construction of the spatial variables. 


\section{References}

Anderton, D. L., Anderson, A. B., Oakes, J. M., \& Fraser, M. R. (1994). Environmental equity - the demographics of dumping. Demography, 31(2), 229-248.

Anselin, L. (2003). Spatial externalities, spatial multipliers, and spatial econometrics. International Regional Science Review, 26(2), 153-166.

Anselin, L., \& Rey, S. (2014). Modern Spatial Econometrics in Practice. Chicago, IL: GeoDa Press LLC.

Anselin, L., Varga, A., \& Acs, Z. (2000). Geographical spillovers and university research: A spatial econometric perspective. Growth and Change, 31(4), 501-515.

Bauer, T., Epstein, G., \& Gang, I. (2002). Herd Effects or Migration Networks? The Location Choice of Mexican Immigrants in the U.S. Bonn, Germany: Institute for the Study of Labor (IZA) Discussion Paper Series.

Been, V. (1994). Locally undesirable land uses in minority neighborhoods - disproportionate siting or market dynamics. Yale Law Journal, 103(6), 1383-1422.

Bowen, W. (2002). An analytical review of environmental justice research: What do we really know? Environmental Management, 29(1), 3-15.

Burton, I., Kates, R. W., \& White, G. F. (1978). The Environment as Hazard. New York: Oxford University Press.

Bustamante, J. A. (2002). Immigrants' vulnerability as subjects of human rights. International Migration Review, 36(2), 333-354.

Call, M. A., \& Voss, P. R. (2016). Spatio-temporal dimensions of child poverty in America, 1990-2010. Environment and Planning A, 48(1), 172-191.

Chay, K., \& Greenstone, M. (2003). The Impact of Air Pollution on Infant Mortality: Evidence from Geographic Variation inPollution Shocks Induced by a Recession. The Quarterly Journal of Economics, 118(3), 1121-1167.

Chiswick, B. R., \& DebBurman, N. (2004). Educational attainment: analysis by immigrant generation. Economics of Education Review, 23(4), 361-379.

Cole, L. W., \& Foster, S. R. (2001). From the Ground Up: Environmental Racism and the Rise of the Environmental Justice Movement. New York, NY: New York University Press.

Collins, T. W., Grineski, S. E., Chakraborty, J., \& McDonald, Y. J. (2011). Understanding environmental health inequalities through comparative intracategorical analysis: Racial/ethnic disparities in cancer risks from air toxics in El Paso County, Texas. Health \& Place, 17(1), 335-344.

Crowder, K., \& Downey, L. (2010). Interneighborhood Migration, Race, and Environmental Hazards: Modeling Microlevel Processes of Environmental Inequality. American Journal of Sociology, 115(4), 1110-1149.

Davis, B., \& Winters, P. (2001). Gender, networks and Mexico-US migration. Journal of Development Studies, 38(2), 1-26.

De Jong, G. F. (2000). Expectations, gender, and norms in migration decision-making. Population Studies-a Journal of Demography, 54(3), 307-319.

Derose, K. P., Escarce, J. J., \& Lurie, N. (2007). Immigrants and health care: Sources of vulnerability. Health Affairs, 26(5), 1258-1268.

DeWaard, J., Kim, K., \& Raymer, J. (2012). Migration Systems in Europe: Evidence From Harmonized Flow Data. Demography, 49(4), 1307-1333.

Ellis, M., Wright, R., \& Townley, M. (2014). The Great Recession and the Allure of New Immigrant Destinations in the United States. International Migration Review, 48(1), 3-33.

EPA. (2015). Risk-Screening Environmental Indicators (RSEI) Methodology Version 2.3.3. Retrieved November 20th, 2015, from https://www.epa.gov/sites/production/files/201508/documents/rsei_methodology_v2_3_3_0.pdf

EPA. (2017). Releases of Chemicals in the 2015 TRI National Analysis. Retrieved February 18, 2017, from https://www.epa.gov/trinationalanalysis/releases-chemicals-2015-tri-national-analysis. 
Evans, G. W., \& Kantrowitz, E. (2002). Socioeconomic status and health: The potential role of environmental risk exposure. Annual Review of Public Health, 23, 303-331.

Fotheringham, S. A., Brunsdon, C., \& Charlton, M. (2002). Geographically Weighted Regression: The Analysis of Spatially Varying Relationships. Chichester: John Wiley \& Sons, Inc.

Franco-Lopez, H., Ek, A. R., \& Bauer, M. E. (2001). Estimation and mapping of forest stand density, volume, and cover type using the k-nearest neighbors method. Remote Sensing of Environment, 77(3), 251-274.

Freeman, C., III. ( 1972). Distribution of Environmental Quality. In A. V. Kneese \& B. T. Bower (Eds.), Environmental quality Analysis: Theory and method in the social science. (pp. 243-278).

Baltimore, MD: The John Hopkins Press.

Garip, F. (2008). Social capital and migration: How do similar resources lead to divergent outcomes? Demography, 45(3), 591-617.

Gee, G. C., Ryan, A., Laflamme, D. J., \& Holt, J. (2006). Self-reported discrimination and mental health status among African descendants, Mexican Americans, and other Latinos in the New Hampshire REACH 2010 Initiative: The added dimension of immigration. American Journal of Public Health, 96(10), 1821-1828.

Gilbert, A., \& Chakraborty, J. (2011). Using geographically weighted regression for environmental justice analysis: Cumulative cancer risks from air toxics in Florida. Social Science Research, 40(1), 273286.

Glaeser, E. (2007). Glaeser EL (2007) The economic approach to cities. National Bureau of Economic Research Working Paper \#13696.

Gober, P., \& Zonn, L. E. (1983). KIN AND ELDERLY AMENITY MIGRATION. Gerontologist, 23(3), 288-294.

Gollini, I., Lu, B., Charlton, M., Brunsdon, C., \& Harris, P. (2015). GWmodel: An R Package for Exploring Spatial Heterogeneity Using Geographically Weighted Models. Journal of Statistical Software, 63(17), 1-50.

Goodnough, A. (2016, January 29, 2016). Flint Weighs Scope of Harm to Children Caused by Lead in Water. New York Times. Retrieved from http://www.nytimes.com/2016/01/30/us/flint-weighsscope-of-harm-to-children-caused-by-lead-in-water.html

Harris, I., Jones, P. D., Osborn, T. J., \& Lister, D. H. (2014). Updated high-resolution grids of monthly climatic observations - the CRU TS3.10 Dataset. International Journal of Climatology, 34(3), 623-642.

Hernandez, M., Collins, T. W., \& Grineski, S. E. (2015). Immigration, mobility, and environmental injustice: A comparative study of Hispanic people's residential decision-making and exposure to hazardous air pollutants in Greater Houston, Texas. Geoforum, 60, 83-94.

Higgs, G., \& Langford, M. (2009). GIScience, environmental justice, \& estimating populations at risk: The case of landfills in Wales. Applied Geography, 29(1), 63-76.

Hunt, K. J., Resendez, R. G., Williams, K., Haffner, S. M., Stern, M. P., \& Hazuda, H. P. (2003). Allcause and cardiovascular mortality among Mexican-American and non-Hispanic white older participants in the San Antonio Heart Study - Evidence against the \&quot;Hispanic paradox\&quot; . American Journal of Epidemiology, 158(11), 1048-1057.

Hunter, L. M. (2000). The spatial association between US immigrant residential concentration and environmental hazards. International Migration Review, 34(2), 460-488.

Hunter, L. M. (2005). Migration and environmental hazards. [Article]. Population and Environment, 26(4), 273-302.

Jennings, J. A., \& Gray, C. L. (2015). Climate variability and human migration in the Netherlands, 18651937. Population and Environment, 36(3), 255-278.

Johnson, K. (2013). Demographic Trends in Nonmetropolitan America: Implications for land use development and conservation. Sociology Scholarship(Paper 46).

Kim, C., Phipps, T. T., \& Anselin, L. (2003). Measuring the benefits of air quality improvement: a spatial hedonic approach. Journal of Environmental Economics and Management, 45(1), 24-39. 
Kim, G., Worley, C. B., Allen, R. S., Vinson, L., Crowther, M. R., Parmelee, P., et al. (2011). Vulnerability of Older Latino and Asian Immigrants with Limited English Proficiency. Journal of the American Geriatrics Society, 59(7), 1246-1252.

Kugler, T., Van Riper, D., Manson, S., Haynes, D. I., Donato, J., \& Stinebaugh, K. (2015). Terra Populus: Workflows for Integrating and Harmonizing Geospatial Population and Environmental Data. Journal of Map \& Geography Libraries, 11(2), 180-206.

Laurian, L., \& Funderburg, R. (2014). Environmental justice in France? A spatio-temporal analysis of incinerator location. Journal of Environmental Planning and Management, 57(3), 424-446.

Lievanos, R. S. (2015). Race, deprivation, and immigrant isolation: The spatial demography of air-toxic clusters in the continental United States. Social Science Research, 54, 50-67.

Maantay, J. (2007). Asthma and air pollution in the Bronx: Methodological and data considerations in using GIS for environmental justice and health research. Health \& Place, 13(1), 32-56.

Maantay, J., \& Maroko, A. (2009). Mapping urban risk: Flood hazards, race, \& environmental justice in New York. Applied Geography, 29(1), 111-124.

Mani, M., \& Wheeler, D. (1998). In Search of Pollution Heavens? Dirty Industry in the World Economy, 1960 to 1995. Journal of Environment and Development, 7(3).

Massey, D. (2010). New Faces in New Places. The Changing Geography of American Immigration (pp. 380). New York: Russell Sage Foundation.

McGlade, M. S., Saha, S., \& Dahlstrom, M. E. (2004). The Latina paradox: An opportunity for restructuring prenatal care delivery. American Journal of Public Health, 94(12), 2062-2065.

McRoberts, R. E., Nelson, M. D., \& Wendt, D. G. (2002). Stratified estimation of forest area using satellite imagery, inventory data, and the k-Nearest Neighbors technique. Remote Sensing of Environment, 82(2-3), 457-468.

Mennis, J. L., \& Jordan, L. (2005). The distribution of environmental equity: Exploring spatial nonstationarity in multivariate models of air toxic releases. Annals of the Association of American Geographers, 95(2), 249-268.

Millo, G., \& Piras, G. (2012). splm: Spatial Panel Data Models in R. Journal of Statistical Software, 47(1), 1-38.

Mohai, P., \& Bryant, B. (1992). Environmental Injustice: Weighing Race and Class as Factors in the Distribution of Environmental Hazards. University of Colorado Law Review, 63(4).

Mohai, P., Lantz, P. M., Morenoff, J., House, J. S., \& Mero, R. P. (2009). Racial and socioeconomic disparities in residential proximity to polluting industrial facilities: evidence from the Americans' Changing Lives Study. American journal of public health, 99 Suppl 3, S649-656.

MPC. (2013). Terra Populus: Beta Version [Machine-readable database].Minnesota Population Center, University of Minnesota: Minneapolis, MN.

MPI. (2015a). European Immigrants in the United States. Washington, DC: Migration Policy Institute.

MPI. (2015b). Immigration to the United States: A Historical Perspective. Washington, DC: Migration Policy Institute.

MPI. (2016a). Asian Immigrants in the United States. Washington, DC: Migration Policy Institute.

MPI. (2016b). South American Immigrants in the Unites States. Washington, DC: Migration Policy Institute.

Nawrotzki, R. J., \& Bakhtsiyarava, M. (2016). International Climate Migration: Evidence for the Climate Inhibitor Mechanism and the Agricultural Pathway. Population, Space \& Place, [in press].

Nawrotzki, R. J., Hunter, L. M., Runfola, D. M., \& Riosmena, F. (2015). Climate change as a migration driver from rural and urban Mexico. Environmental Research Letters, 10(11).

Nichols, P. (2001). From the ground up: Environmental racism and the rise of the environmental justice movement. Ecosystem Health, 7(2), 127-129.

Noh, S., Kaspar, V., \& Wickrama, K. A. S. (2007). Overt and subtle racial discrimination and mental health: preliminary findings for Korean immigrants. American journal of public health, 97(7), 1269-1274. 
Openshaw, S. (1984). The Modifiable Areal Unit Problem, Concepts and Techniques in Modern Geography Norwich, UK: GeoBooks.

Park, L., \& Pellow, D. (2011). The slums of Aspen: immigrants vs. the environment in America's Eden. New York: New York University Press.

Partridge, M. D. (2010). The duelling models: NEG vs amenity migration in explaining US engines of growth. Papers in Regional Science, 89(3), 513-536.

PostGIS. (2015). Open Source Geospatial Foundation, The PostGIS Project.

Poston, D. L., Jr., Zhang, L., Gotcher, D. J., \& Gu, Y. (2009). The effect of climate on migration: United States, 1995-2000. Social Science Research, 38(3), 743-753.

RCoreTeam. (2015). R: A language and environment for statistical computing. Vienna, Austria: $\mathrm{R}$ Foundation for Statistical Computing.

Rivera-Batiz, L. F. (2004). Undocumented workers in the labor market: An analysis of the earnings of legal and illegal Mexican immigrants in the United States. [journal article]. Journal of Population Economics, 12(1), 91-116.

Ruggles, S., Genadek, K., Goeken, R., Grover, J., \& Sobek, M. (2015). Integrated Public Use Microdata Series: Version 6.0 [Machine-readable database].

Schelling, T. C. (1969). MODELS OF SEGREGATION. American Economic Review, 59(2), 488-493.

Shauman, K. A. (2010). Gender Asymmetry in Family Migration: Occupational Inequality or Interspousal Comparative Advantage? Journal of Marriage and Family, 72(2), 375-392.

UNEP. (2016). Factsheet on Human Rights and the Environment. Nairobi: United Nations Environmental Programme.

USCB. (2015a). 2014 American Community Survey. American FactFinder.

USCB. (2015b). Public Use Microdata Areas (PUMAs). Retrieved November 15th, 2015, from https://www.census.gov/geo/reference/puma.html

Vigdor, J. L. (2002). Locations, outcomes, and selective migration. Review of Economics and Statistics, 84(4), 751-755.

Viruell-Fuentes, E. A. (2007). Beyond acculturation: Immigration, discrimination, and health research among Mexicans in the United States. Social Science \& Medicine, 65(7), 1524-1535.

Wingate, M. S., \& Alexander, G. R. (2006). The healthy migrant theory: Variations in pregnancy outcomes among US-born migrants. Social Science \&amp; Medicine, 62(2), 491-498.

Wisner, B., Blaikie, P., Cannon, T., \& Davis, I. (2003). At Risk: natural hazards, people's vulnerability and disasters (Second ed.): ROUTLEDGE.

Zeng, J., \& Batalova, J. (2016). Frequently Requested Statistics on Immigrants and Immigration in the United States. Retrieved October 30th, 2015. 